\title{
Isolation and Characterization of Mycoplasma columbinum and Mycoplasma columborale, Two New Species from Pigeons
}

\author{
TAKAMASA SHIMIZU,' HENNING ERN $\emptyset,{ }^{2}$ AND HIROSHI NAGATOMO
}

Division of Veterinary Science, Faculty of Agriculture, University of Miyazaki, Miyazaki, 880 Japan,' and Institute of Medical Microbiology, University of Aarhus, 8000 Aarhus C, Denmark ${ }^{2}$

\begin{abstract}
Eighteen arginine-positive and 32 glucose-fermenting Mycoplasma strains were isolated from tracheas and oropharynxes of pigeons. Biochemical and serological studies revealed that these isolates were distinguished from all of the currently accepted Mycoplasma species and serogroups. The 18 arginine-positive pigeon strains appear to constitute a new species, for which the name Mycoplasma columbinum is proposed. The type strain of $M$. columbinum is MMP1 (= ATCC $29257=$ NCTC 00000). The 32 glucose-fermenting pigeon strains constitute another new species, for which the name Mycoplasma columborale is proposed. The type strain of $M$. columborale is MMP4 (= ATCC $29258=$ NCTC 00000).
\end{abstract}

During an investigation of Mycoplasmatales in wild birds, 50 Mycoplasma strains were isolated from tracheas and oropharyngeal swabs of pigeons (Columba livia var. domestica). All of them were serologically distinct from strains of the established avian Mycoplasma species (Mycoplasma gallisepticum, M. synoviae, M. meleagridis, $M$. gallinarum, $M$. iners, and $M$. anatis) and from the serogroups of Dierks et al. (6). These 50 pigeon Mycoplasma strains were biochemically and serologically divided into two groups. The present study was undertaken to determine whether these two groups constitute two new species.

\section{MATERIALS AND METHODS}

Mycoplasma strains. The anatomical sources and the designations of 50 strains isolated from healthy pigeons in Miyazaki during 1973 and 1975 and used in this study are given in Table 1 . Strain MMP1, an isolate from the trachea of a healthy pigeon, was selected as the representative of the 18 arginine-positive strains. Strain MMP4, an isolate from the oropharynx of another healthy pigeon, was chosen as the representative of the 32 glucose-fermenting strains. All of the isolates were filter-cloned three times.

Seventy-one type or reference strains of the currently accepted Mycoplasma species and of some serogroups were used for comparative serological tests (Table 2).

Medium. Mycoplasma broth base (Pfizer Diagnostic Division) supplemented with $15 \%$ heat-inactivated swine serum, $0.025 \%$ thallium acetate, and $1,000 \mathrm{U}$ of penicillin per $\mathrm{ml}$ was used. $\beta$-Diphosphopyridine nucleotide (Sigma Chemical Co.) and L-cysteine (200 $\mu \mathrm{g} / \mathrm{ml}$ each) and Eagle vitamin solution (Difco Laboratories; $\times 100,1 \%$ ) were added to the medium for the primary isolation of the strains.

Morphological studies. Two-day-old colonies were microscopically observed at a magnification of $\times 50$. Two-day-old broth cultures were studied at a magnification of $\times 1,000$ with a dark-field microscope. Thin sections of cells from 1-day-old broth cultures of strains MMP1 and MMP4 were examined with an electron microscope. The cultures were washed three times in physiological saline, and cells were fixed in $6.25 \%$ glutaraldeyde and then in $2.0 \%$ osmic acid.

Filtration studies. Filterability of the test strains was determined with 2-day-old broth cultures diluted $1: 10$ in phosphate-buffered saline ( $\mathrm{pH} \mathrm{7.2)}$ with $0.2 \%$ gelatin added. Syringe-type adapters (Millipore Corp.) and membrane filters with average pore sizes of $\mathbf{4 5 0}$ and $220 \mathrm{~nm}$ were used, and the number of colonyforming units (CFU) per milliliter was determined on the original suspension and on filtrate.

Reversion experiments. All of the pigeon $\mathrm{Myco}$ plasma strains were grown in a liquid medium containing no bacterial inhibitors. A loopful of each culture was inoculated on the solid medium without inhibitors. After 2 days of incubation at $37^{\circ} \mathrm{C}$, the plates were examined for bacterial colonies. This examination was repeated five times.

Cholesterol requirements. The test for cholesterol requirement was performed by the method of Edward (7). Two-day-old broth cultures were washed twice in broth base and diluted 10 -fold, and $0.01 \mathrm{ml}$ of each dilution was seeded on the following substrates: (i) serum-free agar; (ii) as i but with $0.5 \%$ bovine serum albumin and $10 \mu \mathrm{g}$ of ethanol-dissolved palmitic acid per ml; (iii) same as ii but with $5 \mu \mathrm{g}$ of ethanoldissolved cholesterol per ml; (iv) same as ii but with 1\% PPLO serum fraction (Difco). The requirement for cholesterol was determined indirectly by the test for susceptibility to digitonin as described by Freundt et al. (8). Filter paper disks (6-mm diameter) were soaked with $0.025 \mathrm{ml}$ of a $1.5 \%$ solution of digitonin (Merck and Co.) and placed on the surface of plates seeded with test strains. Examination of the plates for inhibition of growth was made after 3 days of incubation at $37^{\circ} \mathrm{C}$. 
TABLE 1. Designations and sources of the pigeon strains studied

\begin{tabular}{ccc}
\hline Source & \multicolumn{1}{c}{ Arginine-positive strains } & \multicolumn{1}{c}{ Glucose-fermenting strains } \\
\hline Trachea & $\begin{array}{c}\text { MMP1, MMP2, MMP3, MMP9, MMP14, } \\
\text { MMP20, MMP21, MMP1, MMP72, } \\
\text { MMP130, MMP131, MMP134 }\end{array}$ & $\begin{array}{c}\text { MMP5, MMP13, MMP15, MMP17, MMP19, } \\
\text { MMP70, MMP73, MMP132, MMP133, PF2 }\end{array}$ \\
Oropharynx & $\begin{array}{l}\text { MMP110, MMP111, MMP114, MMP121, } \\
\text { MMP123, MMP127 }\end{array}$ & $\begin{array}{c}\text { MMP4, MMP101, MMP102, MMP103, } \\
\text { MMP105, MMP106, MMP107, MMP108, }\end{array}$ \\
& & MMP109, MMP112, MMP113, MMP115, \\
& & MMP116, MMP117, MMP118, MMP119, \\
& & MMP120, MMP124, MMP126, MMP128, \\
& & \\
\hline
\end{tabular}

Biochemical tests. All of the 50 pigeon strains and the 20 avian type or reference strains were examined for breakdown of substrates in a liquid medium supplemented with $0.5 \%$ glucose, $0.5 \%$ urea, or $1 \%$ arginine. The oxidation/fermentation test was performed by the method of Aluotto et al. (1) on the strains which were positive for the breakdown of glucose. Reduction of 2,3,5-triphenyltetrazolium chloride and potassium tellurite under aerobic and anaerobic conditions; hemolysis of sheep and chicken erythrocytes; production of phosphatase, catalase, caseinase, and gelatinase; and breakdown of maltose, glycogen, starch, sucrose, xylose, lactose, mannose, mannitol, sorbitol, arabinose, and salicin were determined by methods described elsewhere (1). Colonial hemadsorption of chicken erythrocytes was determined by the method of Sato et al. (15). Formation of "film and spots" was tested on a solid medium containing either $0.5 \%$ fresh egg yolk and $15 \%$ swine serum or $20 \%$ horse serum alone. The incubation temperature for all tests was $37^{\circ} \mathrm{C}$, and observations were made for 14 days.

Electrophoretic studies. The electrophoretic patterns of the cell proteins of strains MMP1 and MMP4 were compared with those of arginine-positive and glucose-positive avian reference strains, respectively. The test strains were incubated for $48 \mathrm{~h}$ in tubes of liquid medium from the same batch. Cells were sedimented by centrifugation. The cell proteins were solubilized by suspending them in a solution containing $2 \%$ sodium dodecyl sulfate, $2 \% 2$-mercaptoethanol, and $0.1 \%$ bromophenol blue indicator solution in $0.05 \mathrm{M}$ sodium phosphate ( $\mathrm{pH} 7.1$ ) and then heating the mixture in boiling water for $3 \mathrm{~min}$ (5). A volume of $0.07 \mathrm{ml}$ of extract containing $350 \mu \mathrm{g}$ of proteins was examined in $5 \%$ polyacrylamide gels prepared by the method of Hull (10).

Serological tests. Hyperimmune sera against 71 type or reference strains of the currently accepted Mycoplasma species and of some serogroups (Table 2) were prepared in rabbits at the WHO/FAO Collaborative Center for Animal Mycoplasmas in Aarhus. Pigeon strains MMP1 and MMP4 were tested with these sera by the agar-well modification of the growth inhibition technique of Black (3) and by the indirectimmunofluorescence method described by Rosendal and Black (14). Hyperimmune sera against strains MMP1 and MMP4 were tested against the homologous strains and against all 71 type or reference strains. by the methods cited above. In addition, rabbit antisera against MMP1 and MMP4, as well as against the
20 avian Mycoplasma strains listed in Table 4, were prepared in Miyazaki and used in the metabolism inhibition and cell agglutination tests. For the metabolism inhibition test, the method of Taylor-Robinson et al. (17) was employed for the glucose-fermenting strains including the reference strains of serogroup IJ-K-N-Q-R; with arginine-positive strains, the method of Purcell et al. (13) was used. To prepare the antigens for the cell agglutination test, strains MMP1 and MMP4 were grown in 1 liter of broth for 3 days at $37^{\circ} \mathrm{C}$. Cells were collected by centrifuging the cultures. The deposited cells were washed twice in physiological saline and suspended in saline so as to give 10 times the concentration of MacFarland tube 2. The cell agglutination test was performed with disposable plastic plates, each with 10 shallow depressions $10 \mathrm{~mm}$ in diameter. Physiological saline supplemented with $1 \%$ horse serum was used as the diluent.

\section{RESULTS}

Isolation of mycoplasmas from pigeons. Mycoplasmas were isolated from 19 of 54 $(35.2 \%)$ tracheas and 14 of $21(66.7 \%)$ oropharynxes of pigeons, but none was isolated from 40 reproductive tracts examined. As a rule, a single triple-cloned strain from each source material was selected for this study but, when both glucose-positive and arginine-positive strains were isolated simultaneously, one strain of each was selected. Fifty strains, consisting of 18 argininepositive and 32 glucose-positive strains, were selected in this manner. The sources and designations of these strains are given in Table 1. All of the strains grew anaerobically as well as aerobically without the addition of diphosphopyridine nucleotide.

Morphological characteristics. The 18 arginine-positive pigeon strains exhibited typical "fried-egg" colonies on solid medium containing swine serum, and they produced "film and spots" when grown on a medium containing either $20 \%$ horse serum or $0.5 \%$ egg yolk and $15 \%$ swine serum (Fig. 1). In contrast, film and spots were not formed by any of the 32 glucose-positive strains; these strains produced rather fragile colonies with small centers on both types of media (Fig. 2). Dark-field microscopy of 2-day-old cul- 
TABLE 2. Strains of the currently recognized Mycoplasma species and serogroups used for serological comparison

\begin{tabular}{|c|c|}
\hline Organism or serogroup & Strain $^{a}$ \\
\hline Mycoplasma agalactiae & PG2 \\
\hline M. alkalescens . . . . . . & D12 \\
\hline M. alvi ............. & Ilsley \\
\hline$M$. anatis & 1340 \\
\hline M. arginini & G230 \\
\hline$M$. arthritidis . . . . . . . . & PG6 \\
\hline M. bovigenitalium . . . . . . . & PG11 \\
\hline M. bovirhinis . . . . . . . . & PG43 \\
\hline M. bovis .... & Donetta \\
\hline M. bovoculi & M165/69 \\
\hline M. buccalle & CH20247 \\
\hline M. canadense & $257 \mathrm{C}$ \\
\hline M. canis .... & PG14 \\
\hline M. capricolum & California kid \\
\hline M. caviae $\ldots \ldots \ldots \ldots \ldots$ & G122 \\
\hline M. conjunctivae $\ldots \ldots \ldots \ldots$ & HRC581 \\
\hline M. cynos $\ldots \ldots \ldots \ldots \ldots \ldots$ & H831 \\
\hline$\ldots \ldots \ldots \ldots$ & $462 / 2$ \\
\hline M. edwardii & PG24 \\
\hline M. equirhinis & M432/72 \\
\hline M. faucium . . . & DC333 \\
\hline M. feliminutum & BEN \\
\hline M. felis $\ldots \ldots \ldots \ldots \ldots \ldots$ & $\mathrm{CO}$ \\
\hline$M$. fermentans . . . . . . . . & PG18 \\
\hline M. flocculare . . . . . . . . & Ms42 \\
\hline$M$. gallinarum $\ldots \ldots \ldots \ldots$ & PG16 \\
\hline M. gallisepticum $\ldots \ldots \ldots \ldots$ & PG31 \\
\hline M. gateae . . . . . . . & $\mathrm{CS}$ \\
\hline M. gateae I & H372 \\
\hline M. gateae II & H201 \\
\hline M. hominis. & PG21 \\
\hline M. hyorhinis . . & BTS-7 \\
\hline M. hyosynoviae & S16 \\
\hline M. iners . . . . . & PG30 \\
\hline M. lipophilum . & $\mathrm{MaBy}$ \\
\hline M. maculosum . . . . . . . & PG15 \\
\hline$M$. meleagridis $\ldots \ldots \ldots \ldots$ & 17529 \\
\hline M. moatsii . . . & MK405 \\
\hline M. molare $\ldots \ldots \ldots \ldots$ & H542 \\
\hline M. mycoides subsp. capri . . . . & PG3 \\
\hline M. mycoides subsp. mycoides & PG1 \\
\hline$M$. neurolyticum $\ldots \ldots \ldots \ldots$ & A \\
\hline M. opalescens . . & MH5408 \\
\hline M. orale ......... & CH19299 \\
\hline$M$. ovipneumoniae $\ldots \ldots \ldots$ & Y.98 \\
\hline M. pneumoniae . . . . . . . . & FH \\
\hline M. primatum $\ldots \ldots \ldots \ldots$ & $\mathrm{HRC} 292$ \\
\hline M. pulmonis . . . . . . . . . & PG34 \\
\hline M. putrefaciens . . . . . . . & KS-1 \\
\hline M. salivarium $\ldots \ldots \ldots \ldots \ldots$ & PG20 \\
\hline M. spumans $\ldots \ldots \ldots \ldots \ldots$ & PG13 \\
\hline M. suipneumoniae $\ldots \ldots \ldots \ldots$ & J \\
\hline M. synoviae $\ldots \ldots \ldots \ldots \ldots$ & WVU1853 \\
\hline M. verecundum $\ldots \ldots \ldots \ldots$ & 107 \\
\hline Avian serogroup $\mathbf{C} \ldots \ldots \ldots$ & CKK \\
\hline Avian serogroup $\mathrm{D} \ldots \ldots \ldots$ & $\mathrm{DD}$ \\
\hline Avian serogroup F $\ldots \ldots \ldots \ldots$ & WR1 \\
\hline
\end{tabular}

${ }^{a}$ All strains were from the WHO/FAO Collaborative Center for Animal Mycoplasmas, University of Aarhus, Aarhus, Denmark.
TABLE 2-Continued

\begin{tabular}{|c|c|}
\hline Organism or serogroup & Strain $^{a}$ \\
\hline 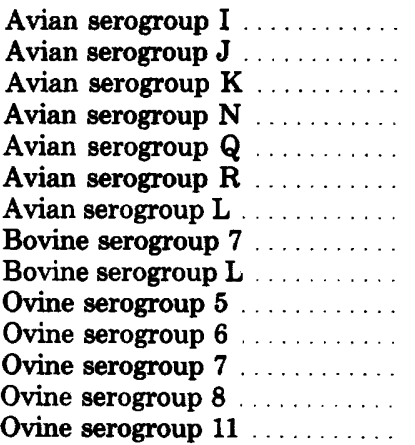 & $\begin{array}{l}695 \\
\text { DJA } \\
\text { DK-CPA } \\
\text { FMN } \\
\text { L3-10B } \\
\text { DRA-0 } \\
694 \\
\text { PG50 } \\
\text { B144P } \\
\text { Goat } 145 \\
\text { Goat } 189 \\
\text { A1343 } \\
\text { Y-goat } \\
\text { 2D }\end{array}$ \\
\hline
\end{tabular}

tures of strains MMP1 and MMP4 showed many pleomorphic organisms such as coccoid, ring, and conglomerate forms. Electron microscopy studies of strain MMP1 revealed pleomorphic cells surrounded by a triple-layered membrane (Fig. 3). The pleomorphism of cells of strain MMP4 was more marked, and the cells were also surrounded by a triple-layered membrane (Fig. 4).

Reversion test. No bacterial-like colonies developed on the noninhibiting substrate during five passages of the 50 pigeon strains.

Filterability. A culture of strain MMP1 contained $6.4 \times 10^{7} \mathrm{CFU} / \mathrm{ml}$, and filtrates of the culture yielded $1.1 \times 10^{6}$ and $1.6 \times 10^{4} \mathrm{CFU} / \mathrm{ml}$ for the 450- and 220-nm-pore-size filters, respectively. A culture of strain MMP4 contained 3.6 $\times 10^{7} \mathrm{CFU} / \mathrm{ml}$ before filtration, and filtrates of this culture contained $6.6 \times 10^{4}$ and $4.0 \times 10^{3}$ $\mathrm{CFU} / \mathrm{ml}$ with 450 - and 220 -nm-pore-size filters, respectively. The remaining 48 strains also passed through 450-nm-pore-size filters.

Test for cholesterol requirement. The suspension of strains MMP1 and MMP4 used to inoculate the media for testing cholesterol requirement contained $2.0 \times 10^{8}$ and $5.1 \times 10^{7}$ $\mathrm{CFU} / \mathrm{ml}$, respectively. Neither MMP1 nor MMP4 grew on serum-free medium i. No growth of MMP4 was observed on medium ii, but poor growth of microcolonies with a small or with no center was observed when an undiluted suspension of MMP1 was inoculated on the same medium and incubated for 6 days. Tenfold to $10^{-5}$ dilutions of the same suspension did not develop colonies on medium ii. Growth of MMP1 developed on both medium iii and medium iv inoculated with undiluted suspension and with $10^{-1}$ to $10^{-3}$ dilutions. Growth of MMP4 on medium iii was positive when an undiluted suspension and a $10^{-1}$ dilution were used as inocula. Growth of strain MMP4 was also posi- 


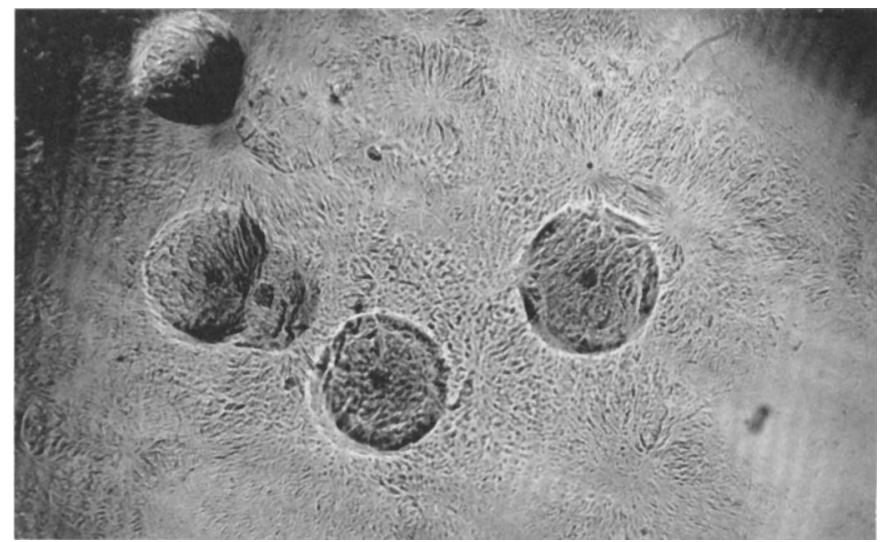

FIG. 1. Production of film and spots by colonies of strain MMP1 grown on medium enriched with $20 \%$ horse serum. $\times 50$.

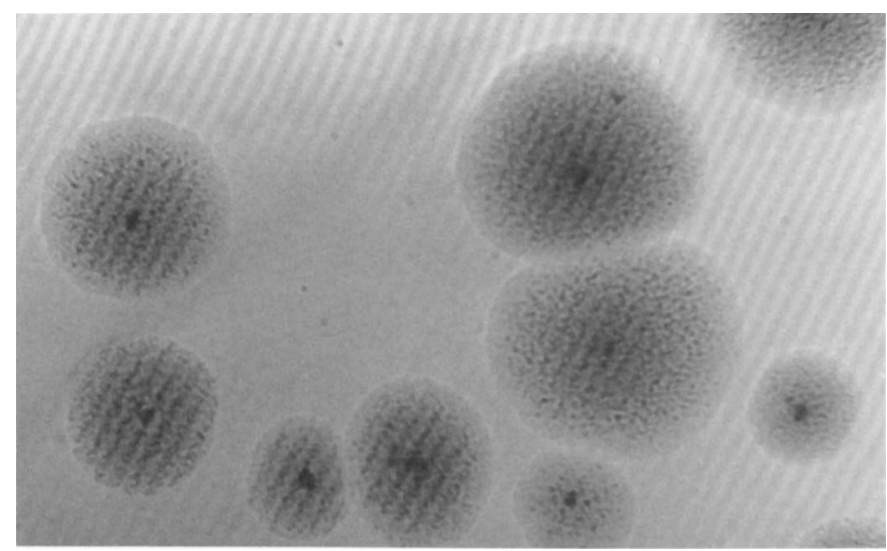

FIG. 2. Colonies of strain MMP4 on medium containing $20 \%$ horse serum. $\times 50$.

tive on medium iv inoculated with an undiluted suspension and with $10^{-1}$ and $10^{-2}$ dilutions.

Strains MMP1 and MMP4 were susceptible to digitonin; an inhibition zone of $8 \mathrm{~mm}$ was observed with the former, and a zone of $12 \mathrm{~mm}$ was observed with the latter. The other $48 \mathrm{pi}$ geon strains were also susceptible to digitonin.

Biochemical characteristics. The results of the biochemical tests with strains MMP1 and MMP4 and the 20 avian reference strains are given in Table 3 . The biochemical patterns of the 17 other arginine-positive strains were identical with that of strain MMP1: they hydrolyzed arginine but were unable to split glucose and urea; were positive for film and spots formation; reduced 2,3,5-triphenyltetrazolium chloride and tellurite under aerobic and anaerobic conditions; lysed sheep and chicken erythrocytes; and were negative for colonial hemadsorption, production of phosphatase, catalase, caseinase, and gelati- nase, and breakdown of the 11 carbohydrates tested.

Strain MMP4 and the 31 other glucose-positive pigeon strains were positive for reduction of 2,3,5-triphenyltetrazolium chloride and tellurite, the hemolysis of sheep and chicken erythrocytes, and the breakdown of maltose, glycogen, and starch. Sucrose was split by 14 of the 32 glucosepositive strains, including MMP4. The 32 strains were negative for arginine hydrolysis; splitting of urea; colonial hemadsorption; formation of film and spots; production of phosphatase, catalase, caseinase, and gelatinase; and the breakdown of xylose, lactose, mannose, mannitol, sorbitol, arabinose, and salicin.

Electrophoretic patterns. The electrophoretic pattern of the cell proteins of strain MMP1 was clearly distinct from those of the argininepositive strains of avian Mycoplasma species and serogroups (Fig. 5). The electrophoretic pat- 


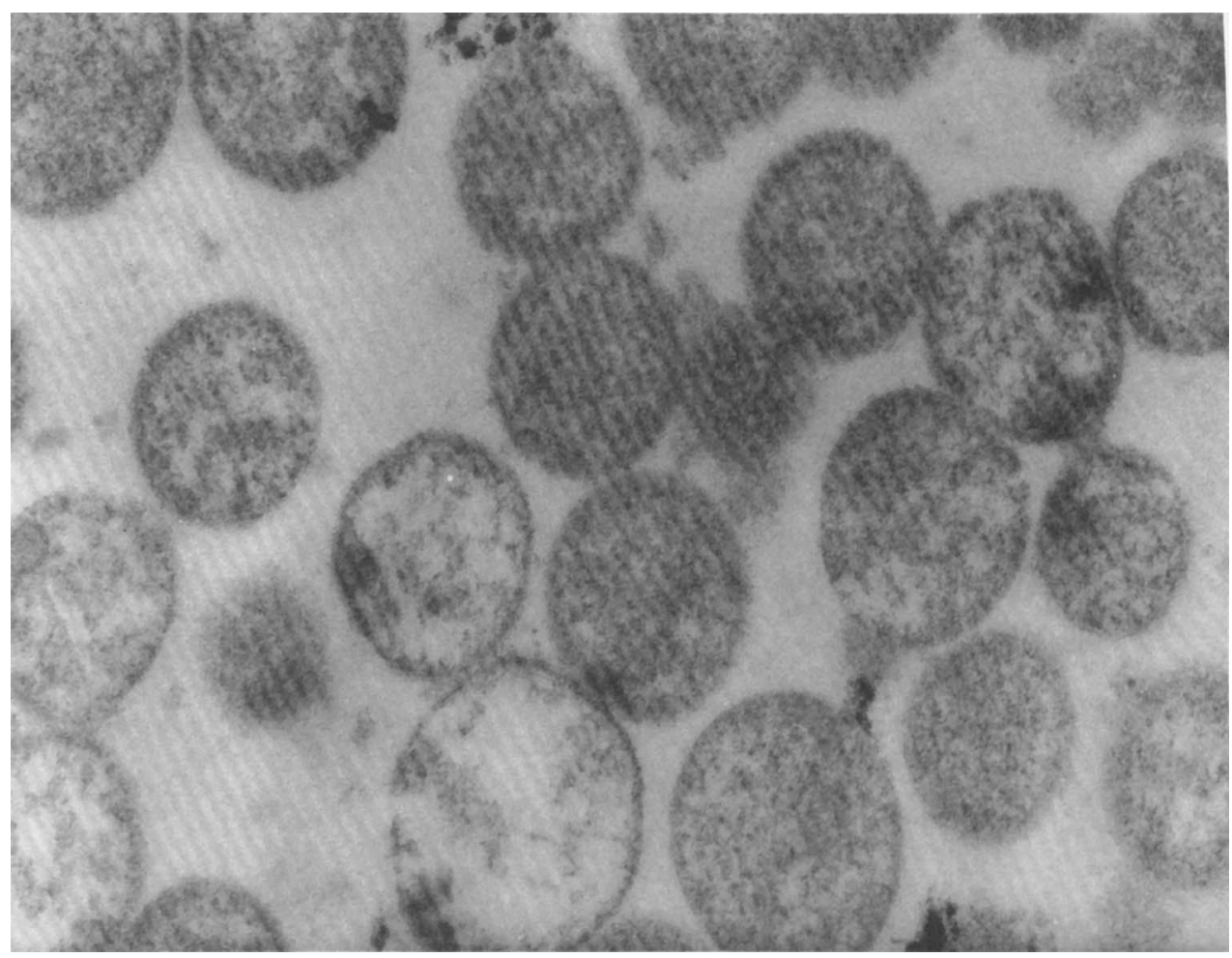

FIG. 3. Thin-section electron micrograph of broth culture pellet of strain MMP1. $\times 40,000$.

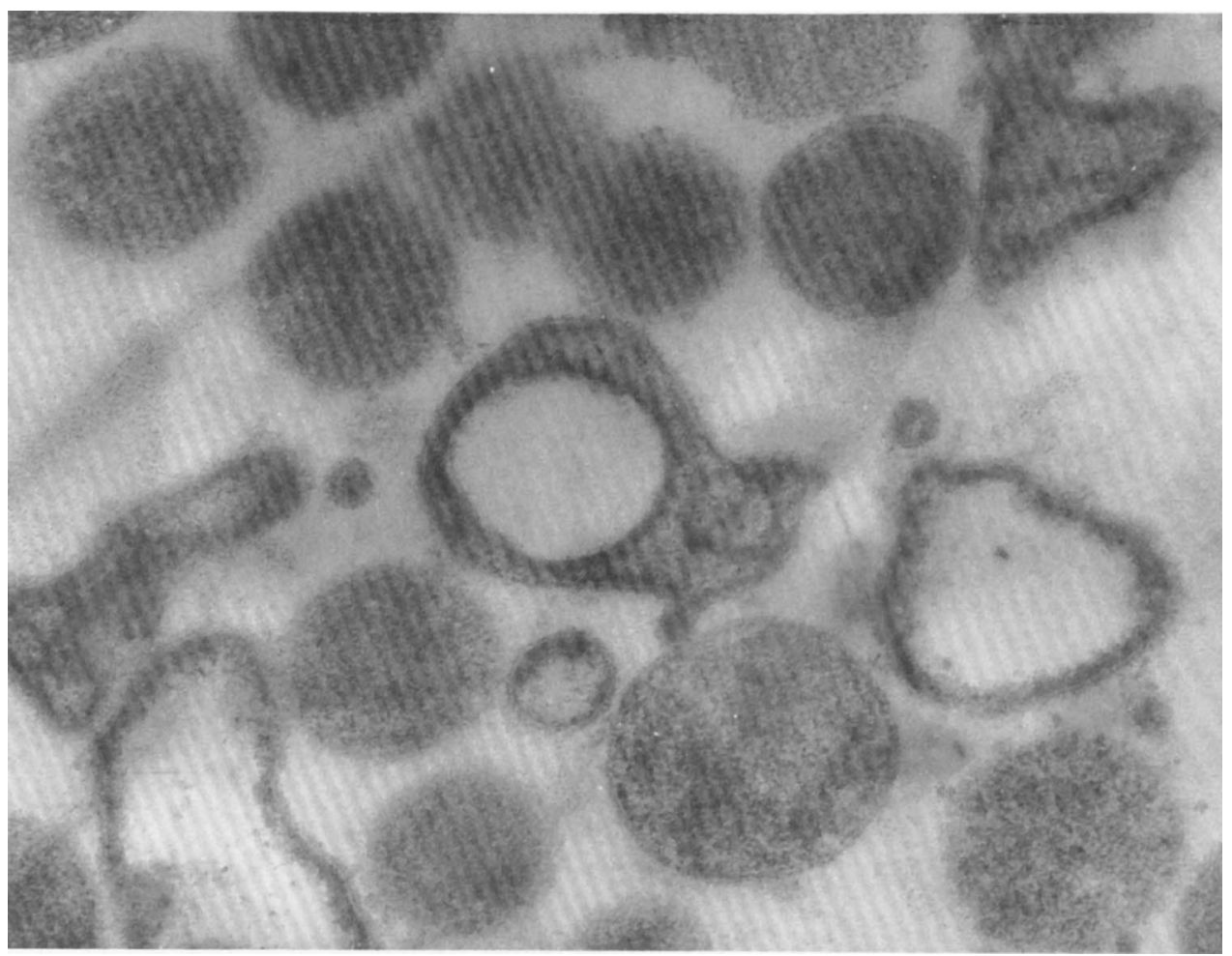

FIG. 4. Thin-section electron micrograph of broth culture pellet of strain MMP4. $\times 45,000$. 
TABLE 3. Main biochemical properties of pigeon strains MMP1 and MMP4 and the reference avian mycoplasma strains ${ }^{a}$

\begin{tabular}{|c|c|c|c|c|c|c|c|}
\hline Strain & $\begin{array}{l}\text { Glucose } \\
\text { fermen- } \\
\text { tation }\end{array}$ & $\begin{array}{l}\text { Argi- } \\
\text { nine hy- } \\
\text { drolysis }\end{array}$ & $\begin{array}{l}\text { Colonial } \\
\text { hemad- } \\
\text { sorption }\end{array}$ & $\begin{array}{l}\text { Phospha- } \\
\text { tase pro- } \\
\text { duction }\end{array}$ & $\begin{array}{l}\text { Film and } \\
\text { spots }\end{array}$ & $\begin{array}{c}\text { TTC reduc- } \\
\text { tion } \\
\text { (Ae/An) }\end{array}$ & $\begin{array}{c}\text { Tellurite re- } \\
\text { duction } \\
\text { (Ae/An) }\end{array}$ \\
\hline Mycoplasma gallisepticum $801 \ldots$ & + & - & + & - & - & $+/+$ & $+/+$ \\
\hline M. synoviae WVU1853 . . . . . & + & - & + & - & + & $-1+$ & $\mathrm{I} / \mathrm{I}$ \\
\hline M. gallinarum $862 \ldots \ldots \ldots \ldots$ & - & + & - & - & + & $+/+$ & $+/ t$ \\
\hline M. gallinarum $\mathrm{R} 49$ & - & + & - & - & + & $-1+$ & $+/+$ \\
\hline M. iners $640 \ldots \ldots \ldots \ldots \ldots \ldots$ & - & + & - & - & $+w$ & $-1-$ & $-1-$ \\
\hline M. iners $867 \ldots \ldots$ & - & + & - & - & + & $-1-$ & $-1-$ \\
\hline M. meleagridis 886 & - & + & - & + & - & $-1-$ & $\mathrm{I} /+$ \\
\hline M. anatis $1340 \ldots$ & + & - & - & + & + & $-1+$ & $-1+$ \\
\hline Serogroup C 859 & + & - & - & - & - & $-1-$ & $+/+$ \\
\hline Serogroup D $8 \ldots$ & + & - & - & - & - & $-1-$ & $+/+$ \\
\hline Serogroup O TC-5 & + & - & - & - & - & $-1-$ & $+/+$ \\
\hline Serogroup P TC-3 & + & - & - & - & - & $-1-$ & $+/+$ \\
\hline Serogroup F SA ... & + & - & - & $+w$ & - & $+/+$ & $-1-$ \\
\hline Serogroup I 695 . & + & + & - & - & - & $-/+$ & $+/+$ \\
\hline Serogroup J 693 . & + & + & - & - & - & $-/+$ & $+/+$ \\
\hline Serogroup K $1805 \ldots$ & + & + & - & - & - & $+w /+$ & $+/+$ \\
\hline Serogroup N PHN-D13 & + & + & - & - & - & $-/+$ & $+/+$ \\
\hline Serogroup Q L3-10 . . . . . . . . & + & + & - & - & - & $+/+$ & $+/ t$ \\
\hline Serogroup R D2497 & + & + & - & - & - & $+/+$ & $+/+$ \\
\hline Serogroup L $694 \ldots$. & - & + & - & - & + & $-1+$ & $+/+$ \\
\hline Pigeon strain MMP1 & - & + & - & - & + & $-1+$ & $+/+$ \\
\hline Pigeon strain MMP4 & + & - & - & - & - & $-1+$ & $+/+$ \\
\hline
\end{tabular}

${ }^{a} M$. anatis 1340 was obtained from the National Institute of Allergy and Infectious Diseases, Bethesda, Md.; the 19 other reference strains were kindly supplied by M. L. Frey, Iowa State University, Ames, Iowa. Abbreviations and symbols: Ae, aerobic; An, anaerobic; +w, weak reaction; I, inhibition of growth; TTC, 2,3,5triphenyltetrazolium chloride.

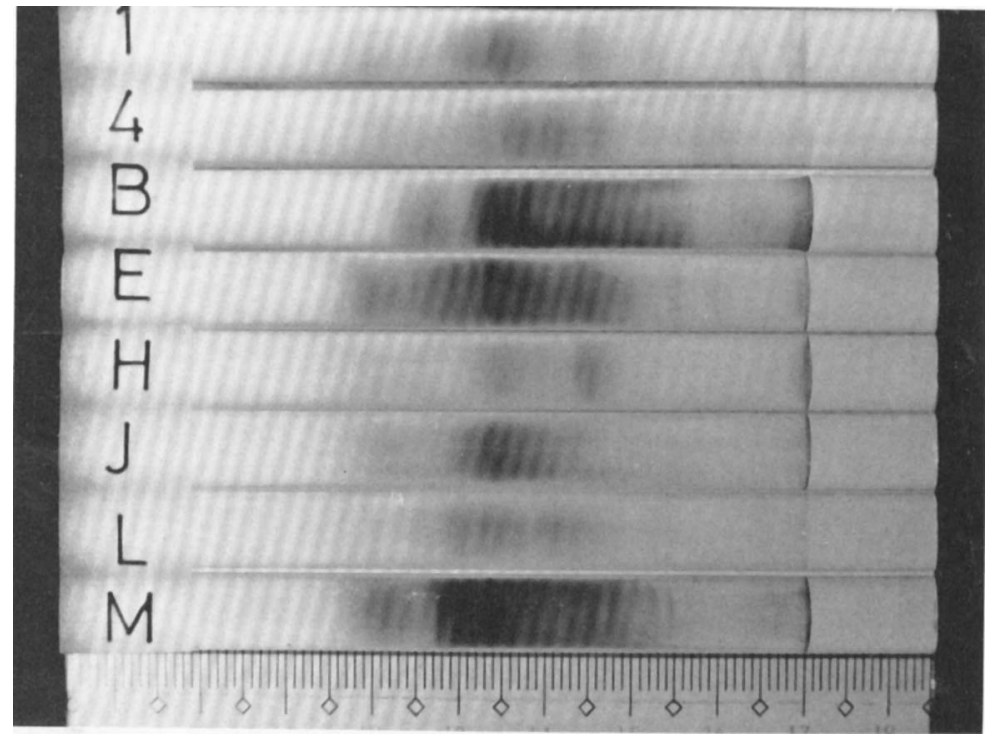

FIG. 5. Electrophoretic patterns of cell proteins of arginine-positive avian reference strains and of the pigeon strains. (1) MMP1; (4) MMP4; (B) M. gallinarum 862; (E) M. iners 640; (H) M. meleagridis 886; (J) serogroup $J$ 693; (L) serogroup L 694; (M) M. gallinarum $R 49$.

tern of strain MMP4 was also different from those of the glucose-positive avian strains (Fig. 6).

Serological tests. Strains MMP1 and
MMP4 were tested with hyperimmune sera against 71 type or reference strains of the currently accepted Mycoplasma species and serogroups by the growth inhibition and indirect- 


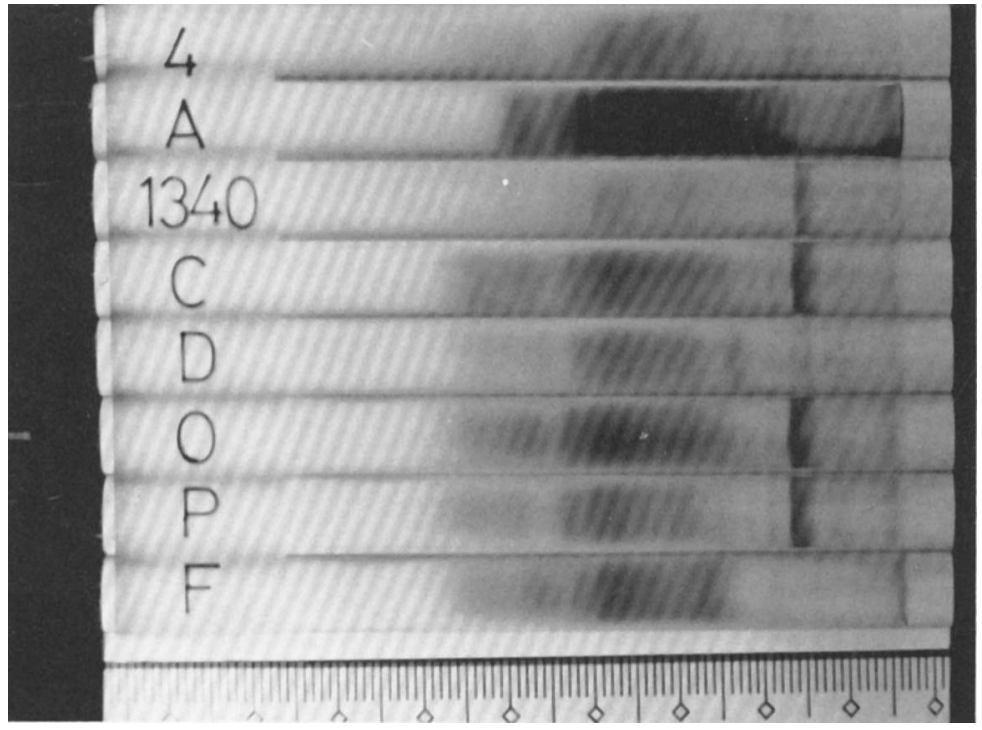

Fí. 6. Electrophoretic patterns of glucose-positive strains. (4) MMP4; (A) M. gallisepticum 801; (1340) M. anatis 1340; (C) serogroup $C$ 859; (D) serogroup $D$ 8; (O) serogroup $O T C-5 ;(P)$ serogroup $P$ TC-3; (F) serogroup $F$ SA.

immunofluorescence techniques. Inhibition of growth of both strains was observed with antiserum against $M$. hyorhinis BTS-7. Since no cross-reaction was observed in the indirect-immunofluorescence test, the reaction in the growth inhibition test was regarded as nonspecific.

Hyperimmune serum against MMP1 resulted in an inhibition zone $6 \mathrm{~mm}$ wide and an indirectimmunofluorescence titer of $\geq 2,560$ against the homologous strain. Strain MMP4 reacted against the homologous hyperimmune serum to give an inhibition zone $7 \mathrm{~mm}$ in width and an indirect-immunofluorescence titer of $\geq 1,280$. No cross-reactions were observed between these two strains in both tests. These antisera were tested against the 71 type or reference strains by the methods mentioned above. Growth of $M$. $m y$. coides subsp. mycoides strain PG1 was inhibited by antiserum against MMP1, and growth of $M$. synoviae WVU1853 was inhibited by antisera against MMP1 and MMP4. No cross-reactions were observed in the indirect-immunofluorescence test, and neither antiserum inhibited growth of $M$. hyorhinis.

None of the 50 pigeon strains represented by MMP1 and MMP4 reacted with antisera against the 20 avian reference strains in either the growth inhibition or the metabolism inhibition test (Table 4). None of the 20 avian reference strains reacted to antisera against MMP1 and MMP4 in either the growth inhibition or the metabolism inhibition test performed in Miya- zaki, nor did they agglutinate whole-cell antigens of strains MMP1 and MMP4, which were agglutinated only by the homologous antisera (Table 4). The 18 arginine-positive pigeon strains listed in Table 1 exhibited growth inhibition zones of 3 to $5 \mathrm{~mm}$ in diameter with antiserum against strain MMP1. Growth of the 32 glucose-positive strains, on the other hand, was inhibited by antiserum against MMP4 and yielded inhibition zones 4 to $5 \mathrm{~mm}$ in diameter.

\section{DISCUSSION}

Although previous reports $(9,12,18)$ have demonstrated the parasitism of pigeons by members of the order Mycoplasmatales, strains belonging to serogroup $\mathrm{L}$ are the only isolates whose taxonomic position has been determined $(2,6,16,19)$. In the present study, 50 isolates were obtained from pigeons and subjected to a taxonomic analysis.

The morphologies of the colonies, the pleomorphic cells in liquid cultures, the observation of triple-layered membranes by electron microscopy, filterability through 450 - and 220 -nm-poresize filters, and the absence of reversion to bacterial colonies indicate that the test strains belong to the order Mycoplasmatales (11). The cholesterol requirement and digitonin susceptibility of these strains place them in the family Mycoplasmataceae. The ability of these strains to split either arginine or glucose and their inability to decompose urea indicate that they belong to the Mycoplasma. 
TABLE 4. Serological reactions of pigeon strains MMP1 and MMP4 to antisera against 20 reference strains of avian Mycoplasma species or serogroups in growth inhibition (GI), metabolism inhibition (MI), and cell agglutination $(A G)$ tests

\begin{tabular}{|c|c|c|c|c|c|c|c|c|}
\hline \multirow{3}{*}{ Antiserum against strain ${ }^{a}$ : } & \multicolumn{8}{|c|}{ Antibody titer against indicated antigen } \\
\hline & \multicolumn{2}{|c|}{ Homologous } & \multicolumn{3}{|c|}{ MMP1 } & \multicolumn{3}{|c|}{ MMP4 } \\
\hline & $\mathrm{GI}^{b}$ & MI & GI & MI & AG & GI & MI & AG \\
\hline Mycoplasma gallisepticum 801 & 4 & 2,560 & 0 & $<10$ & 0 & 0 & $<10$ & 0 \\
\hline M. synoviae WVU1853 . . . . . & 3 & 1,280 & 0 & $<10$ & 0 & 0 & $<10$ & 0 \\
\hline M. gallinarum $862 \ldots \ldots \ldots \ldots$ & 5 & 1,280 & 0 & $<10$ & 0 & 0 & $<10$ & 0 \\
\hline M. gallinarum $\mathrm{R} 49$ & 4 & 1,280 & 0 & $<10$ & 0 & 0 & $<10$ & 0 \\
\hline$M$. iners $640 \ldots \ldots$ & 5 & 5,120 & 0 & $<10$ & 0 & 0 & $<10$ & 0 \\
\hline$M$. iners $867 \ldots \ldots$ & 5 & 1,280 & 0 & $<10$ & 0 & 0 & $<10$ & 0 \\
\hline M. meleagridis 886 & 5 & 640 & 0 & $<10$ & 0 & 0 & $<10$ & 0 \\
\hline M. anatis $1340 \ldots$ & 3 & 5,120 & 0 & $<10$ & 0 & 0 & $<10$ & 0 \\
\hline Serogroup C 859 & 3 & 640 & 0 & $<10$ & 0 & 0 & $<10$ & 0 \\
\hline Serogroup D $8 \ldots$ & 5 & 1,280 & 0 & $<10$ & 0 & 0 & $<10$ & 0 \\
\hline Serogroup O TC-5 & 6 & 2,560 & 0 & $<10$ & 0 & 0 & $<10$ & 0 \\
\hline Serogroup P TC-3 & 5 & 1,280 & 0 & $<10$ & 0 & 0 & $<10$ & 0 \\
\hline Serogroup F SA ... & 7 & 2,560 & 0 & $<10$ & 0 & 0 & $<10$ & 0 \\
\hline Serogroup I 695 & 8 & 10,240 & 0 & $<10$ & 0 & 0 & $<10$ & 0 \\
\hline Serogroup J $693 \ldots$ & 6 & 20,480 & 0 & $<10$ & 0 & 0 & $<10$ & 0 \\
\hline Serogroup K $1805 \ldots$ & 7 & 10,240 & 0 & $<10$ & 0 & 0 & $<10$ & 0 \\
\hline Serogroup N PHN-D13 . . . . . . . . & 8 & 5,120 & 0 & $<10$ & 0 & 0 & $<10$ & 0 \\
\hline Serogroup Q L3-10 . . . . . . . . . & 3 & 5,120 & 0 & $<10$ & 0 & 0 & $<10$ & 0 \\
\hline Serogroup R D2497 & 6 & 20,480 & 0 & $<10$ & 0 & 0 & $<10$ & 0 \\
\hline Serogroup L $694 \ldots$. & 4 & 2,560 & 0 & $<10$ & 0 & 0 & $<10$ & 0 \\
\hline Pigeon strain MMP1 & 5 & 1,280 & 5 & 1,280 & 40 & 0 & $<10$ & 0 \\
\hline Pigeon strain MMP4 & 4 & 5,120 & 0 & $<10$ & 0 & 4 & 5,120 & 80 \\
\hline
\end{tabular}

${ }^{a}$ Sources of the reference strains are given in Table 3.

${ }^{b}$ Zone of growth inhibition in millimeters.

The test strains consisted of two serologically distinct groups: the 18 arginine-positive strains were serologically identical with strain MMP1, whereas the 32 glucose-fermenting strains were serologically identical with strain MMP4. Both groups were biochemically and serologically distinct from each other.

Comparative serological tests of strain MMP1 and MMP4 with type or reference strains of the currently recognized Mycoplasma species and of some serogroups with their hyperimmune sera have revealed that each of these strains represents a new species, since no cross-reactions were observed in the immunofluorescence test and the rections observed in growth inhibition were one-way and were considered to be non-specific.

The name Mycoplasma columbinum sp. nov. (L. adj. columbinus pertaining to a pigeon) is proposed for the arginine-positive pigeon strains. The type strain of $M$. columbinum is MMP1 (= ATCC $29257=$ NCTC 10178), which was isolated from the trachea of a healthy pigeon in 1973. Mycoplasma columborale sp. nov. (L. $\mathrm{n}$. columba pigeon; L. n. os, oris the mouth; M. L. neut. adj. orale of the mouth; M. L. neut. adj. columborale of the pigeon mouth) is the name proposed for the serologically homologous, glu- cose-fermenting pigeon strains. The type strain of $M$. columborale is MMP4 (= ATCC $29258=$ NCTC 10179), a strain isolated from the oropharynx of a healthy pigeon in 1973.

Whether $M$. columbinum and $M$. columborale are pathogenic for pigeons remains to be determined.

\section{ACKNOWLEDGMENTS}

We thank E. A. Freundt, University of Aarhus, Denmark, for his interest in this work and review of the manuscript and Hiroko Yago, University of Miyazaki, Miyazaki, Japan, for the electron micrographs.

This study was supported in part by a grant-in-aid for scientific researches on mycoplasmas (1975-1976, with $\mathrm{M}$. Ogata, University of Tokyo, as the representative) from the Ministry of Education of Japan.

\section{REPRINT REQUESTS}

Address reprint requests to: Dr. T. Shimizu, Division of Veterinary Science, Faculty of Agriculture, University of Miyazaki, Miyazaki, 880 Japan.

\section{LITERATURE CITED}

1. Aluotto, B. B., R. G. Wittler, C. O. Williams, and J. E. Faber. 1970. Standardized bacteriologic techniques for the characterization of Mycoplasma species. Int. J. Syst. Bacteriol. 20:35-58.

2. Barber, T. L., and J. Fabricant. 1971. A suggested reclassification of avian mycoplasma serotypes. Avian Dis. 15:125-138. 
3. Black, F. T. 1973. Modification of the growth inhibition test and its application to human T-mycoplasmas. Appl. Microbiol. 25:528-533.

4. Clyde, W. A., Jr. 1964. Mycoplasma species identification based upon growth inhibition by specific antisera. J. Immunol. 92:958-965.

5. Daniels, M. J., and B. M. Meddins.1973. Polyacrylamide gel electrophoresis of mycoplasma proteins in sodium dodecyl sulfate. J. Gen. Microbiol. 76:239-242.

6. Dierks, R. E., J. A. Newman, and B. S. Pomeroy. 1967. Characterization of avian mycoplasma. Ann. N.Y. Acad. Sci. 143:170-189.

7. Edward, D. G. 1971. Determination of sterol requirement for Mycoplasmatales. J. Gen. Microbiol. 69:205-210.

8. Freundt, E. A., B. E. Andews, H. Ernø, M. Kunze, and F. T. Black. 1973. The sensitivity of Mycoplasmatales to sodium polyanethol sulfonate and digitonin. Zentralbl. Bakteriol. Parasitenkd. Infektionskr. Hyg. Abt. 1 Orig. 225:104-112.

9. Gianforte, E. M., E. L. Jungherr, and R. E. Jacobs. 1955. A serologic analysis of seven strains of pleuropneumonia-like organisms from air sac infection in poultry. Poultry Sci. 34:662-669.

10. Hull, R. 1971. Examination of alfalfa mosaic virus protein on polyacrylamide gels. Virology 45:767-772.

11. International Committee on Systematic Bacteriology, Subcommittee on the Taxonomy of Mycoplasmatales. 1972. Proposal for minimal standards for de- scriptions of new species of the order Mycoplasmatales. Int. J. Syst. Bacteriol. 22:184-188.

12. Mathey, W. J., Jr., H. E. Adler, and P. J. Siddle. 1956. Isolation of a pleuropneumonia-like organism from pigeons. Am. J. Vet. Res. 17:521-522.

13. Purcell, R. H., D. Taylor-Robinson, D. C. Wong, and R. M. Chanock. 1966. A color test for the measurement of antibody to the non-acid-forming human mycoplasma species. J. Epidemiol. 84:51-66.

14. Rosendal, S., and F. T. Black. 1972. Direct and indirect immunofluorescence of unfixed and fixed mycoplasma colonies. Acta. Pathol. Microbiol. Scand. Sect. B 80:615-622.

15. Sato, S., K. Matsui, and Y. Yoshida. 1965. Chicken red blood cell adsorption test for detection of colonies of Mycoplasma gallisepticum developed on agar media. Natl. Inst. Anim. Health Q. 4:45-46.

16. Stipkovits, L., and A. A. El-Ebeedy. 1977. Biochemical and serological studies of avian mycoplasmas. Zentralbl. Veterinaermed. Reihe B. 24:218-230.

17. Taylor-Robinson, D., R. H. Purcell, D. C. Wong, and R. M. Chanock. 1966. A color test for the measurement of antibody to certain mycoplasma species based upon the inhibition of acid production. J. Hyg. 64:91-104.

18. Winterfield, R. W. 1953. Pigeons as a source of the turkey sinusitis agent. Vet. Med. 48:124-125.

19. Yoder, H. W., Jr., and M. S. Hofstad. 1964. Characterization of avian mycoplasma. Avian Dis. 8:481-512. 